\title{
Comparison of biopsychosocial functioning of women of different nationalities in the perimenopausal period
}

\author{
Marta Makara-Studzińska ${ }^{1}$, Karolina Maria Kryś-Noszczyk ${ }^{1}$, Artur Wdowiak $^{2}$, Marzena Kamińska $^{3}$, \\ Szymon Bakalczuk ${ }^{4}$, Grzegorz Bakalczuk ${ }^{2}$
}

${ }^{1}$ Department of Applied Psychology, Medical University of Lublin, Lublin, Poland

2Department of Obstetrics, Gynecology and Obstetrics and Gynecological Nursing, Medical University of Lublin, Lublin, Poland ${ }^{3}$ Chemotherapy Department, Center of Oncology of Lublin Region, Lublin, Poland

${ }^{4}$ Non-Public Health Care Unit 'Ovum Reproduction and Andrology', Lublin, Poland

\section{Abstract}

Introduction: The perimenopausal age is a time of many changes in women's health. Changes in women's health affect all spheres of life, because health is not merely the absence of disease or infirmity but full psychological, physical and social well-being. Presentation and comparison of the biopsychosocial functioning of women of different races and nationalities in perimenopause, identification of the most common menopause symptoms occurring among women and their needs.

Material and methods: Work supported with research examples. Using the PubMed database, the medical literature was searched for works that contain the key words menopause and race or ethnicity published between 1996 and 2013 and available in English. Literature in Polish is a supplementary issue.

Results: Various demographic processes taking place in the countries of Africa, North and South America, Asia and Europe are the basis for observing the situation in perimenopausal women in these countries. Caucasian women living in North America and Europe most often experience the negative symptoms of menopause, hindering daily functioning, and women living in urbanized countries in Asia best assess their health condition, both psychosocial and physical.

Conclusions: Biopsychosocial functioning of women varies among countries. Developing countries should be given the necessary support and financial information to ensure the health and quality of life in perimenopausal women. In most countries of the world there has been observed the need to promote women's health, particularly research aimed at prevention, increasing physical activity and attention to nutrition.

Key words: perimenopausal age, menopause, biopsychosocial functioning.

\section{Introduction}

The perimenopausal period of women is a time of many changes in biopsychosocial functioning. Sometimes, it even lasts for 15 consecutive years, from 45 years of age. The World Health Organization has divided the menopausal life of women into three periods surrounding menopause. The first is the menopausal transition period (premenopause), characterized by irregular menstrual age and generally about 45 to 49 years of age. Perimenopause lasts for about 2 years before menopause and up to 2 years after menopause. During this period, the first biological and endocrine symptoms appear. Postmenopause is the time after the last menstruation, irrespective of whether the menopause was a natural process or was induced artificially [1].

Interest in menopause increased with the increase in the average life expectancy of women and the de- mographic reality, concerning a surplus of women over men in the world's population [2]. Of great importance in the case of biopsychosocial functioning of women in the perimenopausal period are ageing societies, often called nowadays "graying continents" [3]. Not without significance are other demographic changes in the individual countries, such as decline in the birth rate, the increasing age of women giving birth, and changes in family structure. The growing trend for their own health care and the cult of beauty of the human body have found many followers, and the epidemiological statistics as well as the results of numerous scientific studies confirm the increasing problems that pose a challenge to public health on a global basis.

The main objective is to present the differences in the changes in the symptoms occurring in the perimenopausal period in women from different countries and continents. The study is also intended to indicate the 
variety of factors determining the course of the perimenopausal period.

\section{Material and methods}

Using the PubMed database, the medical literature was searched for works that contain the key words menopause and race or ethnicity published in the years 1996-2013 and available in English. Due to the large number of papers that meet the above criteria, we selected those which in a transparent manner present data based on studies conducted among women of different races and nationalities. More than 40 foreign articles were selected that closely meet the selection criteria; 7 of them concern perimenopausal women from Asian countries, 3 articles relate to African countries, and the situation in perimenopausal women in countries in the America are presented on the basis of 4 articles. Among the articles presenting the functioning of women in Europe, 7 were selected, while the situation of women in Poland is presented on the basis of 5 articles published in the "Menopause Review". In close connection with the subject of the work, we also present current ways to relieve menopausal symptoms, by means of 12 foreign and Polish articles (PubMed database). Other items of literature are on similar issues concerning demographic change in Europe. These works are complementary issues.

\section{Results}

The last few years all over the world have seen a continuation of colossal demographic changes. The growing number and proportion of older people is due to the low birth rate and low mortality [4]. Demographic processes of change are taking place faster in developing countries than in developed countries [5]. The new demographics, formed in Europe in the 1990s, is characterized by a significant reduction in fertility, increase of illegitimate births, and a growing number of partners in a consensual union [6].

A review of the literature shows that the number of studies conducted in African countries is the smallest one. Menopause is seen by African women as a time of "relief" from pregnancy and motherhood, but for women without children, this time begins with depressive disorders. African countries are highly diverse in terms of customs and cultural beliefs. In some cultures, women after menopause often strengthen their position in society, and then begin to be treated "on an equal footing" with men. In other cultures it is believed that postmenopausal menstrual bleeding is a negative sign - of being haunted, resulting in delayed medical treatment [7]. Research in 1997 indicated the presence of an early perimenopausal period in African women, which is caused by the numerous children in quick succession. Symptoms of menopause in African women are not different from those typical for other women, but social and economic factors differ. Several authors are of the opinion that among African women in menopause there has not been observed an increase in the incidence of breast cancer. According to other researchers, 50\% of detected cases of breast cancer affect women at a later period, i.e. menopause, indicating the malignant form of cancer [8].

African-American women do not perceive symptoms of menopause as problems for which women should consult a doctor. Dark-skinned women think they are seen as being mentally strong and fully accept all the changes. Compared with Asian, Latin and European women, the most common problem for African women was to maintain a healthy body weight during menopause [9]. In addition, these women experience more inequality in access to health services due to limitations in health insurance. They have higher levels of poverty and disability, higher incidence of lifestyle diseases and a shorter life expectancy. Among darkskinned women, there was a higher risk of heart failure compared with Asian and Latin women and women living in areas of the Pacific [10]. African-American women's knowledge about menopause, social support and the socio-economic situation is not comforting [11].

Since 1994, in Asian countries high rates of mortality from cardiovascular disease have been noted. These data indicators still lag behind those from the United States or the United Kingdom, but the Asian ones are becoming more challenging [12]. A common symptom perceived negatively by Asian women and unusual in studies of women of other nationalities was stiff joints [13]. The most common problems for women in Asia were insomnia and irritability (51\%). Women in Asia occasionally look for advice concerning medication in treatment of symptoms of menopause. They more often use natural or herbal methods which - as proved by the study - are not characterized as being more effective than placebo [14]. There was also a negative attitude towards women taking hormone replacement therapy (43\%), explaining their reluctance with the connection between the use of hormone replacement therapy and increased risk of breast cancer. Among Asian women in the perimenopausal period there is less interest in sex life and withdrawn satisfaction. Women experience discomfort during intercourse, sometimes pain, which has a negative impact according to respondents on the relationship with their partner, quality of life and reduction of femininity. Most Asian women do not discuss their problems of a biological nature with their partners, and only $12 \%$ of women share their experiences with other women [15].

Another interesting study pointed out the connection between the consumption of isoflavones and soy, 
and the alleviation of menopausal symptoms. A review of the current literature does not support the efficacy of alternative therapies in patients diagnosed with contraindications to hormone therapy or feared side effects of hormone treatment, to alleviate or eliminate pain symptoms of the menopausal period [16]. The authors of many studies have reported that phytoestrogens have a positive effect during menopause [17-20]. Herbs such as black cohosh, Chinese angelica, evening primrose or ginseng do not bring an improvement in relieving vasomotor symptoms [14, 21-23]. Researchers appreciate the positive impact of physical activity on weight reduction, which in turn can reduce the severity of menopausal symptoms. The most desirable form of activity for perimenopausal women is yoga, aerobics or swimming [24-26].

A surprising result of the study was the fact that Asian women living in the United States assessed the menopausal period less positively than their fellow citizens remaining in Asia. In a study of 105 women, including 50 women from the city of Mexico, and 55 women from the state of Yucatan, it was observed that menopause symptoms were more severe for women living in metropolitan Mexico City, which may be affected by dependence on Western culture [27].

Women living in big cities, educated and obtaining higher wages for work, remained sexually active longer [28]. Asians cope better with the symptoms of menopause, with additional changes in lifestyle, relaxation, optimistic thinking and yoga. This helps in reducing mood swings [9].

Another report from 2007 provides information on the biopsychosocial functioning of women from India, Pakistan and China. Highly educated women living in urban cities were more susceptible to the symptoms of menopause than women with primary education, living in rural areas [29]. Research conducted in Pakistan by Malik reported that $94 \%$ of perimenopausal women do not see menopause as a medical problem, and only $1.96 \%$ of the women were afraid to use hormone replacement therapy. It should also be noted that $75.5 \%$ of women belonged to the socio-economically poor social stratum. Among women in India, there is a belief that the perimenopausal period is the "beginning of the end", determined by culture, religion and spiritual beliefs. About $60 \%$ of Indian women aged 50 years are widows and suffering in the perimenopausal period from hysteria, anemia, osteoporosis, and poverty [30].

Research conducted in 2012 among women of different origins in Malaysia (including Indian women) found that studied individuals were characterized by a closed attitude toward sexual need during menopause, which leads to the consideration of the introduction of intervention programs in line with the Malaysian culture environment [31].

North and South America is inhabited by women of different races and ethnic groups. Hot flashes are a characteristic symptom of African-American women $(67.8 \%)$ and women of the white race, mostly Americans of European descent. Next, $52.5 \%$ of Latin women complain about hot flashes, compared to only $26.1 \%$ of Asian women. The other most frequently reported symptoms were pain in the muscles and bones, and problems with the urogenital system. In Latin America, most women reported trouble falling asleep. Higher reportability of any problems associated with menopause was reported in North America, comparable to data from Europe [32].

Women living in Europe feel the most numerous perimenopausal symptoms such as hot flashes, sleep disturbances [33] and urogenital system disorders. More than half of Swedish women after the age of 50 experience hot flashes [34]. Lifestyle change to increase of physical activity is an alternative to the use of hormone replacement therapy. Numerous scientific studies indicate a lower risk of cardiovascular disease with the frequent use of physical exercise, particularly in postmenopausal women [35]. A study from Finland showed the danger of the use of hormone replacement therapy and the problems associated with mammography in the diagnosis of breast cancer. The risk was observed in the case of injection estrogen therapy or sequential estrogen-progesterone therapy [36].

Increasing attention is also paid to sexual functioning in menopausal women. Studies in the United Kingdom from 2012 point to the urgent need for extensive research on the effects of replacement therapy on sexual desire. Postmenopausal British women are increasingly seeking help from specialists in diseases associated with sexual functioning [37].

Research from Poland does not show large differences in the prevalence of typical climacteric symptoms like those reported in Europe and in Caucasian women living in North America. There is an intensification of climacteric symptoms along with age, poor material circumstances, living alone and non-use of hormone therapy, which in turn affects the family and professional relationships [38]. The worrying issue is the lack of physical activity of women. Active forms of recreation are often carried out by women who are more affluent. Nearly half of women will experience once in a while a variety of indispositions that cause discomfort, and $14 \%$ say that they feel so bad that it makes their daily functioning harder [39]. Most perimenopausal women used dietary supplements and they do not have a negative attitude towards the use of hormone replacement therapy.

In a study of 2013 from Poland 12,676 women aged 45-69 years took part in Novosibirsk (Russia), Krakow (Poland) and six Czech cities. The aim of this study was to investigate the age of menopause in relation to socioeconomic, behavioral and health factors. Average age of menopause was 50 years in Novosibirsk, 51 years 
in the Czech cities and 52 years in Krakow. Higher education, taking dietary supplements and oral contraceptives were associated with a later age of menopause, while smoking, low physical activity and refraining from alcohol were associated with an earlier onset of menopause. Differences in age of occurrence of menopause between the countries of Central and Eastern Europe were significant and unexplained by a number of risk factors. The results were to a large extent in compliance with studies in other populations [40].

The position of the Panel of Experts of the Polish Menopause and Andropause Society in 2010 is clear and focuses on the practical aspects of treatment in the light of evidence-based medicine. In Poland there are about 9 million women over 46 years of age, in whom there is evidence for use of different forms of hormone therapy. Despite a decline in interest in HRT since 2002, in Poland there was a need to improve the current state of knowledge and individualization of therapy [41].

Despite much discussion, research and medical authorities meeting in 2012, there are still differences between the opinions of scientists on the use of replacement therapy [42]. Primarily, the individualization of hormone replacement therapy is necessary [43]. Professional societies such as the International Menopause Society (IMS), the European Menopause and Andropause Society (EMAS), and the Polish Menopause and Andropause Society (PTMA) currently recommend transdermal therapy as effective and safe [44-46].

The position of the Panel of Experts of the PTMA of 2012, regarding the selection of the route of administration in the treatment of menopausal hormones, indicates that the percutaneous route has good efficacy and a favorable safety profile [41]. The North American Menopause Society (NAMS) does not state a clear advantage of any of the routes of administration of estrogen therapy [47].

\section{Discussion and conclusions}

Forecasts of anticipated changes suggest that in future years the number of women in the menopausal age will increase. Systems of health and social care will be under-funded in many countries, which can cause numerous problems in access to services for women entering the perimenopausal period and force them to cope with menopausal symptoms on their own using the latest available methods. All demographic changes discussed above have an impact on the biopsychosocial functioning of women during perimenopause, and this should be the basis for the creation of efficient systems of care and support for women in different countries. The needs of women in developing countries and those in developed countries will be presented differently.

There are a number of inconsistencies in the proposed ways to prevent and treat symptoms of the pe- rimenopausal period, so it is necessary to conduct further in-depth research in this area. It is also necessary to provide information and financial support for developing countries to improve the quality of life of women and increase their average life expectancy. There is a great need to promote a healthy lifestyle among perimenopausal women, in particular relaxation techniques, increased physical activity, and healthy eating.

\section{Disclosure}

Authors report no conflict of interest.

\section{References}

1. World Health Organization. Research on the menopause in the 1990 s. Report of a WHO Scientific Group. WHO Technical Report Series 866, Geneva, 1996; pp. 1-3.

2. Austad SN. Starzenie się. In: W głąb ludzkiego ciała. Polish edition for National Geographic Society, Warszawa 2001; pp. 241-245.

3. Szukalski P. Proces starzenia się ludności - przyczyny, etapy, konsekwencje. In: Geriatria z elementami gerontologii ogólnej. Podręcznik dla lekarzy i studentów. Grodzicki T, Kocemba J, Skalska A (eds.). Via Medica, Gdańsk 2007; pp. 13-17.

4. Kliszcz J. Czynniki demograficzne, część 2. Forum Opieki Długoterminowej Medi. Stowarzyszenie na Rzecz Opieki Długoterminowej i Pomocy Społecznej „Dom Pod Stońcem”, Toruń 2008; p. 19.

5. World Bank. World development report: investing in health. Oxford University Press, New York 1996

6. Kachaniuk H. Opieka nad zdrowiem osób starszych. W: Zdrowie Publiczne. Kulik TB, Latalski M (eds.). Czelej, Lublin 2002; pp. 298-301.

7. Wambula LT. African perceptions and myths about menopause. African Medical and Research Foundation, PubMed, 2010, Nairobi, Kenya.

8. Sidobe EH. Menopause in Africa. East Afr Med J. Centre Marc Sankale, B.P. 5062,1997, Fann, Dakar (Senegal).

9. Roser MA. Race, ethnicity may affect how women experience menopause, UT research says. 2010, PubMed: American - Statesman Staff.

10. Eaton CB, Abdulbaki AM, Margolis KL, et al. Racial and ethnic differences in incident hospitalized heart failure in postmenopausal women: the Women's Health Initiative. Circulation 2012; 126: 688-696.

11. Mathunjwa-Dlamini TR, Gary FA, Yarandi HA, Mathunjwa MD. Personal characteristics and health status among southern rural African-American menopausal women. J Natl Black Nurses Assoc 2011; 22: 59-67.

12. Ministry of Health and Welfare. Vital Statistics. Statistics and Information Department, Ministry of Health and Welfare, Tokyo 1996.

13. Takeshi A. Demography of the menopause and pattern of climacteric symptoms in the East Asian region. First Consensus Meeting on Menopause in the East Asian Region: Department of Obstetrics and Gynaecology, Tokyo, Japan, 2000.

14. Pockaj BA, Gallagher JG, Loprinzi CL. Phase III double-blind, randomized, placebo-controlled crossover trial of black cohosh in the management of hot flashes: NCCTG trial NO1CC1. J Clin Oncol 2006; 24: 2836-2841.

15. Rekers H. Asian Menopause Survey. VP Medical Affairs, NV Organon 2007.

16. Sobstyl M, Tkaczuk-Włach J, Sobstyl J, Jakiel G. Czy istnieje skuteczna alternatywa dla terapii hormonalnej w leczeniu objawów menopauzalnych? Prz Menopauzalny 2013; 12: 92-96.

17. Gold EB, Block G, Crawford S, et al. Lifestyle and demographic factors in relation to vasomotor symptoms: baseline results from the Study of Women's Health Across the Nation. Am J Epidemiol 2004; 159: 1189-1199.

18. Quella SK, Loprinzi CL, Barton DL, et al. Evaluation of soy phytoestrogens for the treatment of hot flashes in breast cancer survivors: A North Central Cancer Treatment Group Trial. J Clin Oncol 2000; 18: 1068-1074.

19. Tice JA, Ettinger B, Ensrud K, et al. Phytoestrogen supplements for the treatment of hot flashes: the Isoflavone Clover Extract (ICE) Study: a randomized controlled trial. JAMA 2003; 290: 207-214. 
20. Nelson HD, Vesco KK, Haney E, et al. Nonhormonal therapies for menopausal hot flashes: systematic review and meta-analysis. JAMA 2006 295: 2057-2071.

21. Hirata JD, Swiersz LM, Zell B, et al. Does dong quai have estrogenic effects in postmenopausal women? A double-blind, placebo-controlled trial. Fertil Steril 1997; 68: 981-986.

22. Wiklund IK, Mattsson LA, Lindgren R, Limoni C. Effects of a standardized ginseng extract on quality of life and physiological parameters in symptomatic postmenopausal women: a double-blind, placebo-controlled trial. Swedish Alternative Medicine Group. Int J Clin Pharmacol Res 1999; 19: 89-99.

23. Chenoy R, Hussain S, Tayob Y, et al. Effect of oral gamolenic acid from evening primrose oil on menopausal flushing. BMJ 1994; 308: 501-503.

24. Lindh-Astrand L, Nedstrand E, Wyon Y, Hammar M. Vasomotor symptoms and quality of life in previously sedentary postmenopausal women randomised to physical activity or estrogen therapy. Maturitas 2004 48: 97-105.

25. Chattha R, Raghuram N, Venkatram P, Hongasandra NR. Treating the climacteric symptoms in Indian women with an integrated approach to yoga therapy: a randomized control study. Menopause 2008, 15: 862-870.

26. Carson JW, Carson KM, Porter LS, et al. Yoga of Awareness program for menopausal symptoms in breast cancer survivors: results from a randomized trial. Support Care Cancer 2009; 17: 1301-1309.

27. Carranza-Lira S, Quiroz González BN, Alfaro Godinez HC, May Can AM. Comparison of climacteric symptoms among women in Mexico City and women of a Mayan community of Yucatan. Ginecol Obstet Mex 2012 80: 644-649.

28. Loh FH. Menopause and the Asian woman. Is she different from women of other ethnicities? Menopausal Medicine 2007; 15: S6-S10.

29. Zhao G, Wang L, Yan R. Menopausal symptoms: experience of Chinese women. Climacteric 2000; 3: 135-144.

30. Kimmick G, Broadwater G, Vitolins M. Hot flashes in breast cancer survivors an association with calcium supplement use. Int J Womens Health 2010; 2: 291-294.

31. Wong LP, Awang H, Jani R. Midlife crisis perceptions, experiences, helpseeking, and needs among multi-ethnic malaysian women. Women Health 2012; 52: 804-819.

32. Heinemann K, Ruebig A, Potthoff P, et al. The Menopause Rating Scale (MRS) scale: a methodological review. Health Qual Life Outcomes 2004 2: 45 .

33. Polo-Kantola P, Saaresranta T, Polo O. Aetiology and treatment of steep disturbances during perimenopause and postmenopause. CNS Drugs 2001; 15: 445-452.
34. Rödstörm K, Bengtsson C, Lissner L, et al. A longitudinal study of the treatment of hot flushes: the population study of women in Gothenburg during a quarter of a century. Menopause 2002; 9: 156-161.

35. Asikainen TM, Kukkonen-Harjula K, Miilunpalo S. Exercise for health for early postmenopausal women. Sports Med 2004; 34: 753-778.

36. Njor SH, Hallas J, Schwartz W, et al. Type of hormone therapy and risk of misclassification at mammography screening. Menopause 2011; 18: 171-177.

37. Rosen RC, Maserejian NN, Connor MK, et al. Characteristics of premenopausal and postmenopausal women with acquired, generalized hypoactive sexual desire disorder: the Hypoactive Sexual Desire Disorder Registry for women. Menopause 2012; 19: 396-405.

38. Skrzypulec V, Naworska B, Drosdzol A. Analiza wpływu objawów klimakterycznych na funkcjonowanie i jakość życia kobiet w okresie okołomenopauzalnym. Prz Menopauzalny 2007; 6: 96-101.

39. Synowiec-Piłat M. Wybrane społeczne wyznaczniki jakości życia 50-letnich Polek w kontekście ich sytuacji zdrowotnej. Prz Menopauzalny 2010; 9: 385-389.

40. Stepaniak U, Szafraniec K, Kubinova R, et al. Age at natural menopause in three central and eastern European urban populations: The HAPIEE study. Maturitas 2013; 75: 87-93.

41. Dębski R, Paszkowski T, Pawelczyk L. Terapia hormonalna okresu menopauzalnego - stan wiedzy w 2010 r. Stanowisko Zespołu Ekspertów Polskiego Towarzystwa Menopauzy i Andropauzy. Prz Menopauzalny 2010; 9: 121-127.

42. Fenton A, Panay N. The Women's Health Initiative - a decade of Progress. Climacteric 2012; 15: 205.

43. Bińkowska M, Jakiel G. Hormonalna terapia zastępcza 11 lat po Women's Health Initiative - kiedy i jakich korzyści się spodziewać? Prz Menopauzalny 2013; 12: 1-4.

44. Cushman M, Kuller LH, Prentice R, et al. Estrogen plus progestin and risk of venous thrombosis. JAMA 2004; 292: 1573-1580.

45. Woźniakowska E, Milart P, Woźniak S, et al. Standardy hormonalnej terapii zastępczej po Women's Health Initiative - przegląd najnowszych doniesień dotyczących znaczenia drogi podania dla profilu bezpieczeństwa terapii. Prz Menopauzalny 2013; 12: 83-86.

46. Tremollieres F, Brincat M, Erel CT, et al. EMAS position statement: Managing menopausal women with a personal or family history of VTE. Maturitas 2011; 69: 195-198.

47. Söderqvist G, Murkes D, Lundström E, Leifland K. Different effects between percutaneous estradiol/oral progesterone and oral conjugated equine estrogens/medroxyprogesterone acetate on mammographic breast density. Climacteric 2011; 14 suppl 1: 63 